\title{
ADHD subtype-specific cognitive correlates and association with self-esteem: a quantitative difference
}

\author{
Parviz Molavi ${ }^{1}$, Mehriar Nadermohammadi ${ }^{*}$, Habibeh Salvat Ghojehbeiglou', Carmelo M. Vicario ${ }^{2}$, \\ Michael A. Nitsche ${ }^{3}$ and Mohammad Ali Salehinejad $3,4,5^{*}$
}

\begin{abstract}
Background: Attention-deficit hyperactivity disorder (ADHD) is a major neurodevelopmental disorder with heterogeneous symptoms, subtypes, and cognitive deficits. Cognitive deficits are central to ADHD pathophysiology and one potential source of heterogeneity in ADHD. Subtype-specific cognitive correlates are not, however, well-studied. We explored cognitive correlates of ADHD subtypes based on the Wechsler Intelligence Scale for Children (WISC-IV) scores. We also assessed subtype-specific self-esteem rating in ADHD subtypes and explored its association with cognitive correlates.

Methods: One hundred thirty-nine children with ADHD (80.6\% boy, 19.4\% girl) were categorized into the predominantly "hyperactive (ADHD-H)", "inattentive (ADHD-I)" and "combined (ADHD-C)" subtype based on their symptoms and scores on the Kiddie Schedule for Affective Disorders and Schizophrenia (K-SADS-PL) and Conners Parent-Rating Scale (CPRS-RS). They were then individually administrated the WISC-IV and completed a self-esteem inventory. Group differences in the WISC-IV indices and their predictability in discriminating ADHD subtypes were analyzed.

Results: We found a quantitative differentiation of cognitive abilities among ADHD subtypes with "working memory" as the most compromised cognitive domain. ADHD-I had the poorest cognitive profile while ADHD-H scored highest in all cognitive domains. Importantly, cognitive abilities were negatively correlated with inattention and positively correlated with hyperactive symptoms. Moreover, self-esteem ratings were positively correlated with the cognitive domains and were rated differently based on the subtypes. ADHD-H, with the highest cognitive strength, reported the highest level of self-esteem among all subtypes.

Conclusions: ADHD subtype-specific symptoms, cognitive deficits, and self-esteem problems should be considered for precise diagnosis and effective and personalized treatment in ADHD in light of further supporting evidence and assessments. Cognitive interventions might be more compatible with and effective in inattentive and combined subtypes of ADHD. Working memory improving-based interventions can benefit all ADHD subtypes. A supportive educational system in school and providing adjunct supportive interventions should be considered for children with ADHD as well.
\end{abstract}

Keywords: ADHD, ADHD subtype, Cognition, WISC-IV, Working memory, Self-esteem, Personalized medicine

\footnotetext{
* Correspondence: m.nadermohammadi@arums.ac.ir; salehinejad@ifado.de

'Department of Psychiatry, Fatemi Hospital, School of Medicine, Ardabil University of Medical Sciences, Ardabil, Iran

${ }^{3}$ Department of Psychology and Neurosciences, Leibniz Research Centre for Working Environment and Human Factors, Dortmund, Germany

Full list of author information is available at the end of the article
}

(c) The Author(s). 2020 Open Access This article is licensed under a Creative Commons Attribution 4.0 International License, which permits use, sharing, adaptation, distribution and reproduction in any medium or format, as long as you give appropriate credit to the original author(s) and the source, provide a link to the Creative Commons licence, and indicate if changes were made. The images or other third party material in this article are included in the article's Creative Commons licence, unless indicated otherwise in a credit line to the material. If material is not included in the article's Creative Commons licence and your intended use is not permitted by statutory regulation or exceeds the permitted use, you will need to obtain permission directly from the copyright holder. To view a copy of this licence, visit http://creativecommons.org/licenses/by/4.0/. The Creative Commons Public Domain Dedication waiver (http://creativecommons.org/publicdomain/zero/1.0/) applies to the data made available in this article, unless otherwise stated in a credit line to the data. 


\section{Background}

Attention-deficit hyperactivity disorder (ADHD) is a major neurodevelopmental disorder with heterogeneous symptoms, subtypes and treatment response. A precise description of the pathophysiology underlying ADHD is difficult due to its neuropsychological heterogeneity [1] and substantial overlap between ADHD and typically developing children [2]. Cognitive deficits, especially executive dysfunctions, are central to ADHD psychopathology [3] and among the primary treatment targets by pharmacological [4] and novel treatment approaches [5, 6]. These cognitive deficits are also heterogeneous in ADHD and thus individual differences in cognitive profile should be considered as well [7]. One aspect of heterogeneity in ADHD symptoms and cognitive deficits is its subtypes [8, 9] which includes a predominantly hyperactive (ADHD$\mathrm{H}$ ), inattentive (ADHD-I), and combined (ADHD-C) subtype. These subtypes are discerned from each other by the presence of specific symptoms [10], however, little is known about neuro-functional and cognitive differentiation of ADHD subtypes [11].

Furthermore, it is still elusive whether a specific subtype is critical to consider when examining treatment effects. For example, a recent study suggests that the effectiveness of neurofeedback treatment on the executive functioning of children with ADHD is subtypespecific [12]. ADHD-I showed improved performance on the execution of an action in an experimental Go/NoGo task while the ADHD-C showed improved ability to withhold a prepotent response tendency in NoGo trials. Recent reviews of non-invasive brain stimulation studies in ADHD also suggests that the efficacy of the treatment could be different in ADHD subtypes [5, 6]. Identifying subtype-specific profiles in ADHD, especially cognitive profile, is thus a timely and important topic in the field and is in line with recent findings from neuroimaging studies indicating subtype-specific pattern of activity in different brain regions $[13,14]$.

Previous studies showed that the Wechsler Intelligence Scale for Children (WISC) provides a relatively comprehensive profile of cognitive strengths and weaknesses and is commonly used for cognitive evaluation in the clinical pediatric population. Application of WISC in ADHD also confirms that it reliably differentiates between ADHD patients and healthy controls [15, 16]. Moreover, it can provide knowledge about specific cognitive strengths and weaknesses in ADHD [17-21], used in designing therapeutic and educational interventions, and employed as a diagnostic marker in children with ADHD [17, 22-24]. However, the cognitive strengths and weaknesses of ADHD subtypes are not adequately explored in the previous studies in ADHD while several neuropsychological distinctions in ADHD subtypes (especially ADHD-I vs ADHD-C) have been identified [25].
Similar to subtype-specific cognitive deficits, selfesteem and social functioning in ADHD subtypes are not well-studied and the available studies are even more limited. Lower ratings of self-esteem in ADHD patients compared to the healthy control, regardless of ADHD subtypes, have been reported in previous studies [2628 ]. These studies also showed that the treatment of ADHD symptoms was associated with the improvement of self-esteem scores [27] suggesting that self-esteem and ADHD symptoms (including cognitive deficits) are relevant for treatment efficacy. Nevertheless, subtypesspecific ratings of self-esteem and its association with cognitive deficits require further investigation.

The purpose of the present study was, therefore, to explore cognitive correlates of ADHD subtypes based on the WISC-IV scores in a relatively large sample size $(n=$ 139). We also performed a discriminative analysis to evaluate if the cognitive profile of each ADHD subtype can predict group membership. We further assessed the level of self-esteem in each ADHD subtypes to determine any associations between subtype-specific cognitive correlates and self-esteem ratings in ADHD.

\section{Methods \\ Participants}

One hundred thirty-nine children with ADHD (80.6\% boy, $19.4 \%$ girl, mean age $=8.20 \pm 2.50)$, referred to the Fatemi Hospital at Ardabil University of Medical Sciences, were included in this study. The data was collected in the child psychiatry division of the hospital which is dedicated to the diagnosis and treatment of child and adolescence psychiatric disorders, including neurodevelopmental disorders (e.g. ADHD, autism, learning disabilities). Participants' recruitment took place from mid-2017 until the end of 2019. The inclusion criteria were: (1) ADHD diagnosis according to the DMS-5 criteria by a licensed psychiatrist and a child psychologist, (2) moderate to severe score in the parent or teacher version of the Conners' Parent Rating Scale (CPRS) in addition to an independent diagnosis made by psychiatrist/psychologist, (3) being 6-15 years old, (4) and no current and history of psychiatric, neurodevelopmental disorders and chronic physical illness. All participants were on medication treatment when recruited for the experiment however, there were prevented from the medication $24 \mathrm{~h}$ before testing to ensure that WISC-IV performance was not affected by medication as suggested by previous studies [21, 29, 30]. The study was performed according to the latest version of the Declaration of Helsinki and approved by the ethics committee of the local University. Participants' parents were instructed about experimental procedures and gave their written informed consent. Demographic information is summarized in Table 1. 
Table 1 Demographic information

\begin{tabular}{|c|c|c|c|c|c|}
\hline \multicolumn{6}{|l|}{ Demographic information } \\
\hline Variable & & & value & $p$ & Group difference ${ }^{*}$ \\
\hline \multirow[t]{4}{*}{ Sample size (n) } & & & 139 & & \\
\hline & subtype & ADHD-H (\%) & $71(51.1 \%)$ & & \\
\hline & & ADHD-I (\%) & $35(25.2 \%)$ & & \\
\hline & & ADHD-C (\%) & $33(23.7)$ & & \\
\hline \multirow[t]{4}{*}{ Age } & Mean (SD) & Total & $8.20(2.50)$ & 0.001 & ADHD-H $<$ ADHD-I \\
\hline & & ADHD-H & $7.45(2.45)$ & & \\
\hline & & ADHD-I & $9.54(2.29)$ & & \\
\hline & & ADHD-C & $8.42(2.26)$ & & \\
\hline \multirow[t]{5}{*}{ Child order among siblings } & $1 s t$ & ADHD-H/I/C & $41 / 18 / 27$ & & \\
\hline & 2nd & ADHD-H/I/C & $22 / 8 / 5$ & & \\
\hline & $3 r d$ & ADHD-H/I/C & $8 / 7 / 0$ & & \\
\hline & 4 th & ADHD-H/I/C & $0 / 1 / 0$ & & \\
\hline & 5th and higher & ADHD-H/I/C & $0 / 1 / 1$ & & \\
\hline Gender (n) & Male (female) & & $112(27)$ & & \\
\hline \multirow[t]{9}{*}{ CPRS-RS } & Inattaention & ADHD-H (SD) & $26.97(4.81)$ & 0.001 & ADHD-I > ADHD-H \\
\hline & & ADHD-I (SD) & $40.60(4.37)$ & & ADHD-C > ADHD-H \\
\hline & & ADHD-C (SD) & $42.72(4.48)$ & & \\
\hline & Hyperactivity & ADHD-H (SD) & $33.11(4.37)$ & 0.001 & ADHD-H > ADHD-I \\
\hline & & ADHD-I (SD) & $23.42(4.69)$ & & ADHD-C > ADHD-I \\
\hline & & ADHD-C (SD) & $40.66(4.18)$ & & \\
\hline & ADHD-index & ADHD-H (SD) & $59.14(4.54)$ & 0.001 & ADHD-C > ADHD-I \\
\hline & & ADHD-I (SD) & $64.42(6.26)$ & & ADHD-C > ADHD-H \\
\hline & & ADHD-C (SD) & $83.30(7.40)$ & & \\
\hline
\end{tabular}

Note: SD Standard Deviation, ADHD-H Predominantly hyperactive, ADHD-I Predominantly inattentive, ADHD-C Combined, CPRS-RS Conners Parent Rating ScaleRevised: Short form. Between-group differences in demographic continuous variables were explored by F-test. * indicates that only significant group difference between ADHD subtypes are presented.

\section{Measures \\ Kiddie schedule for affective disorders and schizophrenia (K-SADS-PL)}

The K-SADS-PL (3) is a semi-structured interview for assessing psychiatric diagnoses in children and adolescents from 6 to 18 years old. It assesses the present, history of psychiatric disorders, and the severity of symptoms based on the DSM-IV. The K-SADS-PL-P is especially sensitive at diagnosing patients with ADHD, major depressive disorder, bipolar disorder, general anxiety disorder, post-traumatic stress disorder, and substance use disorder. The test-retest reliability and kappa coefficients are reported excellent for the present and lifetime diagnosis of major psychiatric disorders. A native-language version of the scale used in this study with good-to-excellent concurrent validity in diagnosing current major disorders [31]. The Kappa agreements for most diagnoses are higher than 0.4 and the test-retest reliability is 0.87 .

\section{Conners' parent rating scale-revised: short version (CPRS-}

RS)

The revised version of Conners' Rating Scale [32] has three forms; parent, teacher and self-report form and each form has a short and long version. The CPRS-RS used in this study contains 27 items and measures symptoms in four subscales: 1) oppositional subscale, 2) inattention, 3) hyperactive/impulsive, and 4) ADHD Index. Each item is presented in a 4-point Likert scale ranging from Not True at All (1) to Very Much True (4). The cut-off point for clinical diagnosis of ADHD is reported differently and we used scores higher than 59 based on CPRS-RS guidelines which is indicative of "higher average score". The items are based on DSM diagnostic criteria for ADHD. Psychometric properties of the CPRSRS are reported adequate as demonstrated by good internal reliability coefficients, high test-retest reliability and effective discriminative power [33]. The psychometric properties of the native version of the CPRS are 
reported good and reliable and demonstrated to be useful in discriminating children with ADHD from typically developing individuals [34].

\section{Wechsler intelligence scale for children (WISC-IV)}

The WISC-IV is an individually administered test battery that assesses intelligence in school-aged children (from 6 to 16 years of age) [35, 36]. The 4th edition included 10 subtests yielding to four index scores that combine into one FSIQ. The index scores include (1) Verbal Comprehension Index (VCI), (2) Perceptual Reasoning Index (PRI), (3) Work Memory Index (WMI), and (4) Processing Speed Index (PSI). Analyzing WISC-IV profiles are suggested as useful differential diagnosis tools, particularly in distinguishing between "real ADHD" and pseudo-ADHD [37, 38].

\section{Coopersmith self-esteem (CSE) inventory}

The 58-items CSE with high reliability of 0.88 and validity [39] was used to measure the level of self-esteem in participants. CSE is one of the most commonly-used measure of self-esteem in healthy and clinical populations [40]. In CSE, self-esteem total score ranges from 0 to 50. Scores higher than 25 indicate high levels and scores lower than 25 indicate a low level of total selfesteem score. The total self-esteem score is the compound score consisting of four subscales in including global self-esteem, social self-esteem, family self-esteem, and educational/professional self-esteem. These subscales have a separate score and combination of them represents total self-esteem score. The CSE thus measures self-esteem as a global score but it yields a specific score for each subscale as well. The CSE has reliability and validity [41] and the Cronbach's $\alpha$ coefficient and split-half reliability are reported to be 0.83 and 0.84 , respectively $[42,43]$.

\section{Procedure}

139 children in this study were consecutive referrals to our child psychiatry hospital who were diagnosed with ADHD. After we received institutional review board approval, children with ADHD and their parents were interviewed by a psychiatrist based on the CPRS-RS and K-SADS-PL and were categorized into ADHD-I, ADHD$\mathrm{H}$, and ADHD-C accordingly. Twenty-four hours before the testing day, the patients that were on medication stopped taking the medication. They were then administrated the WISC-IV and completed the self-esteem inventory. All tests were conducted in the same testing room. The order of tests was randomized.

\section{Statistical analysis}

We used IBM Statistical Package for the Social Sciences (SPSS) for Windows, version 24 (SPSS Inc., Chicago, IL,
USA) for data analysis. A one-way analysis of variance (ANOVA) and Bonferroni-corrected $\mathrm{t}$-tests were applied to examine group differences for the major WISC-IV indices, including the VCI, PRI, WMI, PSI, and the fullscale intelligence quotient (FSIQ). It is of note that the potential covariate effect of age was controlled as FSIQ and indices scores are estimated by age-scaled scores and thus age was not entered a covariate in the analysis. A separate similar ANOVA was conducted on the rating of self-esteem domains. Our data met the ANOVA linear assumptions and Leven's test was used to examine the homogeneity of variances. Additionally, we performed a discriminant analysis to explore whether WISC-IV indices scores, as predictor variables, can predict grouping of ADHD patients into ADHD-I, ADHD$\mathrm{H}$, and ADHD-C subtypes. Correlational analyses between the outcome measures were calculated using the Pearson correlation (two-tailed). A significance level of $p<.05$ was used for all statistical comparisons.

\section{Results \\ Cognitive profile differences in ADHD subtypes}

The results of ANOVA showed significant differences between ADHD subtypes that were revealed in the FSIQ and all indices of VCI, PRI, WMI, and PSI (Fig. 1, Table 2). Bonferroni-corrected post hoc t-tests revealed that ADHD-I, compared to the ADHD-H, scored lower in the FSIQ $(t=4.21, p<0.001)$ and all indices of VCI $(t=4.20, p<0.001)$, PRI $(t=2.85, p=0.013)$, WMI $(t=$ $2.90, p=0.011)$, and PSI $(t=4.84, p<0.001)$. Moreover, ADHD-I scores in the VCI $(t=2.59, p=0.028)$ and PSI $(t=2.67, p=0.023)$ indices were significantly lower than ADHD-C. No significant difference between ADHD-H vs ADHD-C was found in any of the indices. In sum, WMI was the weakest (regardless of ADHD subtype), VCI was the strongest index, and FSIQ score was 3 points lower than 90 (Fig. 1).

\section{Discriminant analysis and predictive ability}

We used discriminant analysis to see whether subtests scores of the WISC-IV, as predictor variables, can predict grouping of ADHD patients into ADHD-I, ADHD$\mathrm{H}$, and ADHD-C. Results of the discriminant analysis showed a significant function $(p=0.001)$ that accounted for $90.7 \%$ of the discriminative ability of the WISC-IV subtests in predicting ADHD group membership (Chisquare $=113.27, \mathrm{df}=20, p=0.001)$. The canonical correlation between predictor variables and grouping was $\mathrm{R}=$ 0.727. Correct grouping of the function for ADHD-I, ADHD- $\mathrm{H}$, and ADHD-C was 57.1, 84.5, and $45.5 \%$ respectively. Moreover, the discriminant function could correctly classify $68.3 \%$ of the individuals or identified the group to which the individuals belong (Table 3). Finally, we calculated coefficients of the WISC-IV subtests, 


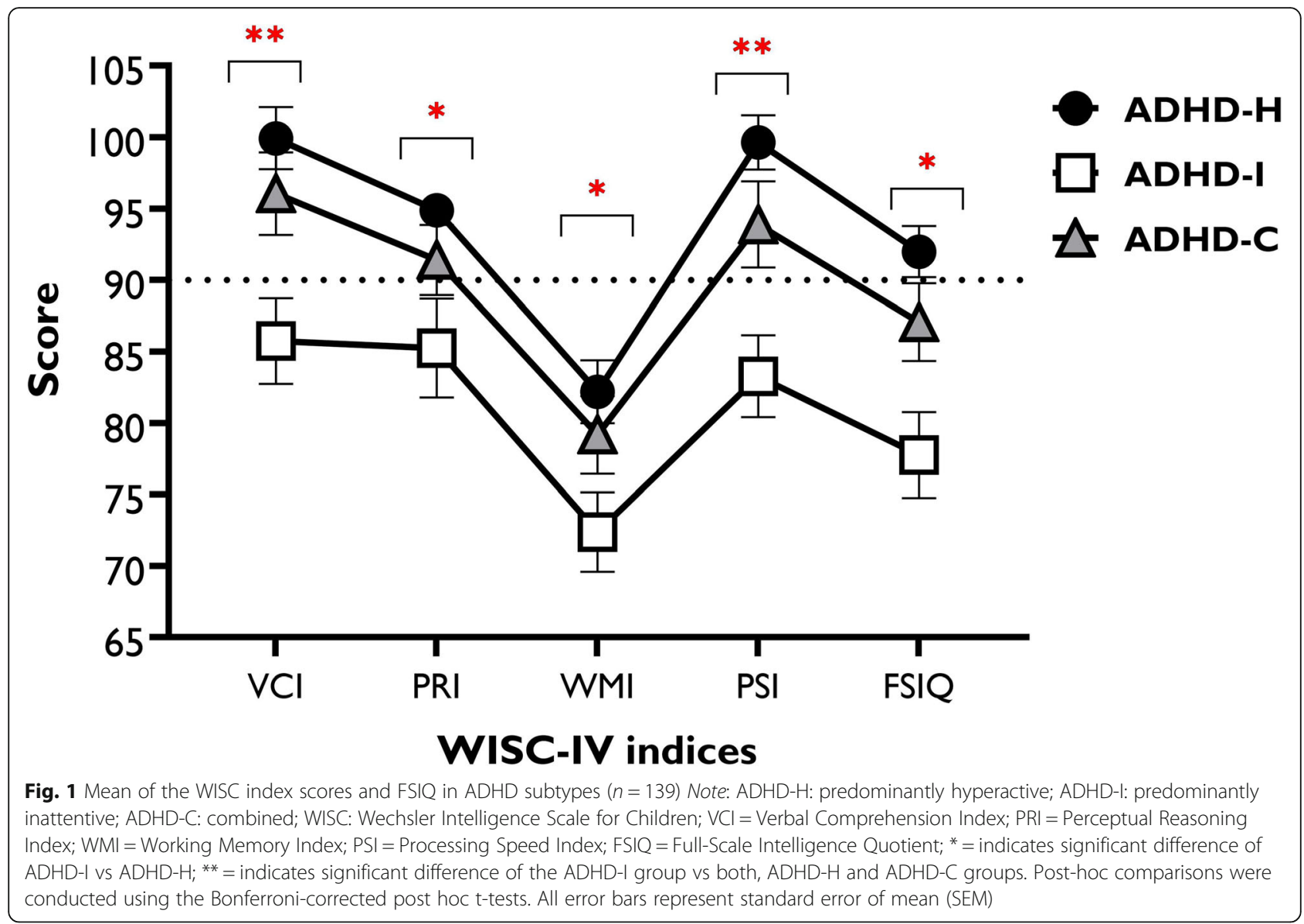

Table 2 ANOVA results for the group differences in the WISC indices and self-esteem rating

\begin{tabular}{|c|c|c|c|c|c|c|c|}
\hline \multicolumn{8}{|l|}{ WISC-IV } \\
\hline \multirow[t]{2}{*}{ variable } & \multirow[t]{2}{*}{ indices } & \multicolumn{6}{|c|}{ Group Mean (SD) } \\
\hline & & ADHD-H & ADHD-I & ADHD-C & $\mathrm{F}$ & $p$-value & $n_{p}^{2}$ \\
\hline \multirow[t]{5}{*}{ WISC-IV } & $\mathrm{VCl}$ & $99.94(18.27)$ & $85.74(17.72)$ & $96.06(16.58)$ & 7.52 & $<.001$ & .10 \\
\hline & PRI & $94.90(9.22)$ & $85.25(20.47)$ & $91.42(14.08)$ & 5.58 & .005 & .076 \\
\hline & WMI & $82.19(18.59)$ & $72.37(16.44)$ & $79.18(15.57)$ & 3.74 & .026 & .052 \\
\hline & PSI & $99.64(15.83)$ & $83.28(16.98)$ & $93.90(17.35)$ & 11.48 & .001 & .144 \\
\hline & FSIQ & $92.00(15.12)$ & $77.77(17.77)$ & $87.06(15.63)$ & 9.33 & $<.001$ & .121 \\
\hline \multicolumn{8}{|c|}{ Self-esteem (CSE) } \\
\hline \multirow[t]{2}{*}{ variable } & domain & \multicolumn{6}{|c|}{ Group Mean (SD) } \\
\hline & & ADHD-H & ADHD-I & ADHD-C & $F$ & $p$-value & $\eta_{p}^{2}$ \\
\hline \multirow[t]{5}{*}{ CSE } & Global & $21.11(2.18)$ & $18.14(3.44)$ & $17.06(3.89)$ & 24.65 & $<.001$ & .266 \\
\hline & Total & $38.52(5.79)$ & $33.00(8.18)$ & $32.30(7.00)$ & 13.18 & $<.001$ & .162 \\
\hline & Social & $6.45(1.54)$ & $5.57(2.26)$ & $5.69(1.64)$ & 3.72 & .027 & .052 \\
\hline & Educational & $4.94(1.88)$ & $3.82(2.39)$ & $4.12(2.24)$ & 3.85 & .024 & .054 \\
\hline & Family & $5.98(1.93)$ & $5.45(1.40)$ & $5.42(1.75)$ & 1.64 & .198 & .024 \\
\hline
\end{tabular}

Note: WISC Wechsler Intelligence Scale for Children, $A D H D-H$ predominantly hyperactive, $A D H D-I$ predominantly inattentive, $A D H D-C$ Combined, $V C I$ Verbal Comprehension Index, PRI Perceptual Reasoning Index, WMI Working Memory Index, PSI Processing Speed Index, FSIQ Full-Scale Intelligence Quotient, CSE Coopersmith Self-esteem Inventory; Post-hoc comparisons were conducted using the Bonferroni-corrected post-hoc t-tests. All error bars represent s.e.m.; significant results are bolded $(p<0.5)$ 
which can specify the contribution of each WISC-IV subtests to distinguishing or discriminating ADHD subtypes. The vocabularies (0.508), similarities (0.364) and symbol search (0.258) subscales had the most significant correlation with a discriminant function (Table 3).

\section{Self-esteem rating}

Results of the ANOVA showed significant differences between ADHD subtypes in the global and total self-esteem rating and a significant main effect of subtypes was found (Table 2). Bonferroni-corrected post hoc analysis revealed that ADHD-H had a significantly higher total self-esteem compared with ADHD-I $(t=7.39, p<0.001)$ and ADHDC $(t=8.16, p<0.001)$. Similarly, ADHD-H patients had a significantly higher global self-esteem compared with ADHD-I $(t=3.97, p<0.001)$ and ADHD-C $(t=5.32, p<$ $0.001)$. No significant differences were found in the subdomains of self-esteem between the groups (Fig. 2).

\section{Correlational analyses}

Cognitive indices of the WICS-IV were positively correlated with ratings of self-esteem indicating that cognitive deficits were associated with lower self-esteem. This positive correlation was observed in all of the WICS-IV indices (VCI, PRI, WMI, PSI, FSIQ) and all of the selfesteem domains except for the family self-esteem (Table 4). Furthermore, we found interesting associations between the WICS-IV indices and attentional vs hyperactivity scores. Cognitive deficits were negatively correlated with attentional symptoms which means that more attentional deficits were associated with poor performance on the WICS-IV indices. In contrast, performance on the WICS-IV indices was positively correlated with hyperactivity/impulsivity symptoms (Table 4). This pattern of association is in line with the quantitative difference between the ADHD-I and ADHD-H with better scores on WICS-IV indices for the latter group. Finally, all of the self-esteem domains, except for the family selfesteem, were negatively correlated with inattention symptoms but not hyperactivity.

\section{Discussion}

In the present study, we explored subtype-specific cognitive correlates in 139 children with ADHD based on the WISC-IV. We also assessed self-esteem ratings in ADHD subtypes. Our results show that ADHD-I has the most impaired cognitive profile among all ADHD subtypes and is mostly discriminated with ADHD-H, with the least impaired cognitive functions. Our results further suggest a quantitative differentiation of cognitive profiles among ADHD subtypes with working memory as the most compromised cognitive domain with the lowest value in ADHD-I. Moreover, we found a converging pattern of ADHD subtype-specific differences in self-esteem rating with a significantly higher-rated self-esteem in ADHD-H compared to ADHD-I and ADHD-C.

With regard to subtype-specific cognitive correlates, we found a quantitative differentiation of cognitive profiles among ADHD subtypes regardless of WISC-IV domains in line with previous works [7, 44, 45]. This suggests that all ADHD subtypes display similar cognitive deficits with WM as the most impaired domain but the extent to which ADHD symptoms are close to inattentive vs hyperactive subtype determines the level of impairment. This is in line with the results of Roberts et al. (2017) that found group difference in executive dysfunction of ADHD subtypes based on gradations of EF impairments. The group with poor set-shifting/speed, close to ADHD-I subtype in our study, was the most severely impaired one and the intact task performance group (close to ADHD-H in our study) was relatively unimpaired in executive functioning task performance [7]. This finding is in line with a previous study based on a sample size of 1038 children with ADHD that found those with cognitive subtype (close to ADHD-I in our sample) exhibit information processing deficits (PSI index in our sample) compared to subtypes with more predominately behavioral problems (ADHD-H in our sample) [46]. This study also reported that ADHD subtypes can be described on a continuum of severity which is supported by our findings.

Table 3 Results of discriminant analysis about predicted group membership

\begin{tabular}{|c|c|c|c|c|c|c|c|}
\hline \multicolumn{4}{|c|}{ Eigenvalues } & \multicolumn{4}{|l|}{ Wilks' Lambda } \\
\hline Function & Eigenvalue & $\%$ of variance & Canonical $r$ & Wilks Lambda & Chi-square & df & Sig \\
\hline 1 & 1.122 & 90.7 & .727 & .423 & 113.279 & 20 & .000 \\
\hline 2 & .115 & 9.3 & .322 & .896 & 14.370 & 9 & .110 \\
\hline \multirow[t]{2}{*}{ Groups } & & N (\%) & & & Total & & \\
\hline & & ADHD-H & ADHD-I & ADHD-C & & & \\
\hline ADHD-H & & $60(84.5)$ & $6(8.5)$ & $5(7.0)$ & $71(100.0)$ & & \\
\hline ADHD-I & & $2(5.7)$ & $20(57.1)$ & $13(37.1)$ & $35(100.0)$ & & \\
\hline ADHD-C & & $8(24.2)$ & $10(30.3)$ & $15(45.5)$ & $33(100.0)$ & & \\
\hline
\end{tabular}

a.68,3\% of original grouped cases correctly classified

Note: $A D H D-H$ predominantly hyperactive, $A D H D-I$ Predominantly inattentive, $A D H D-C$ Combined 


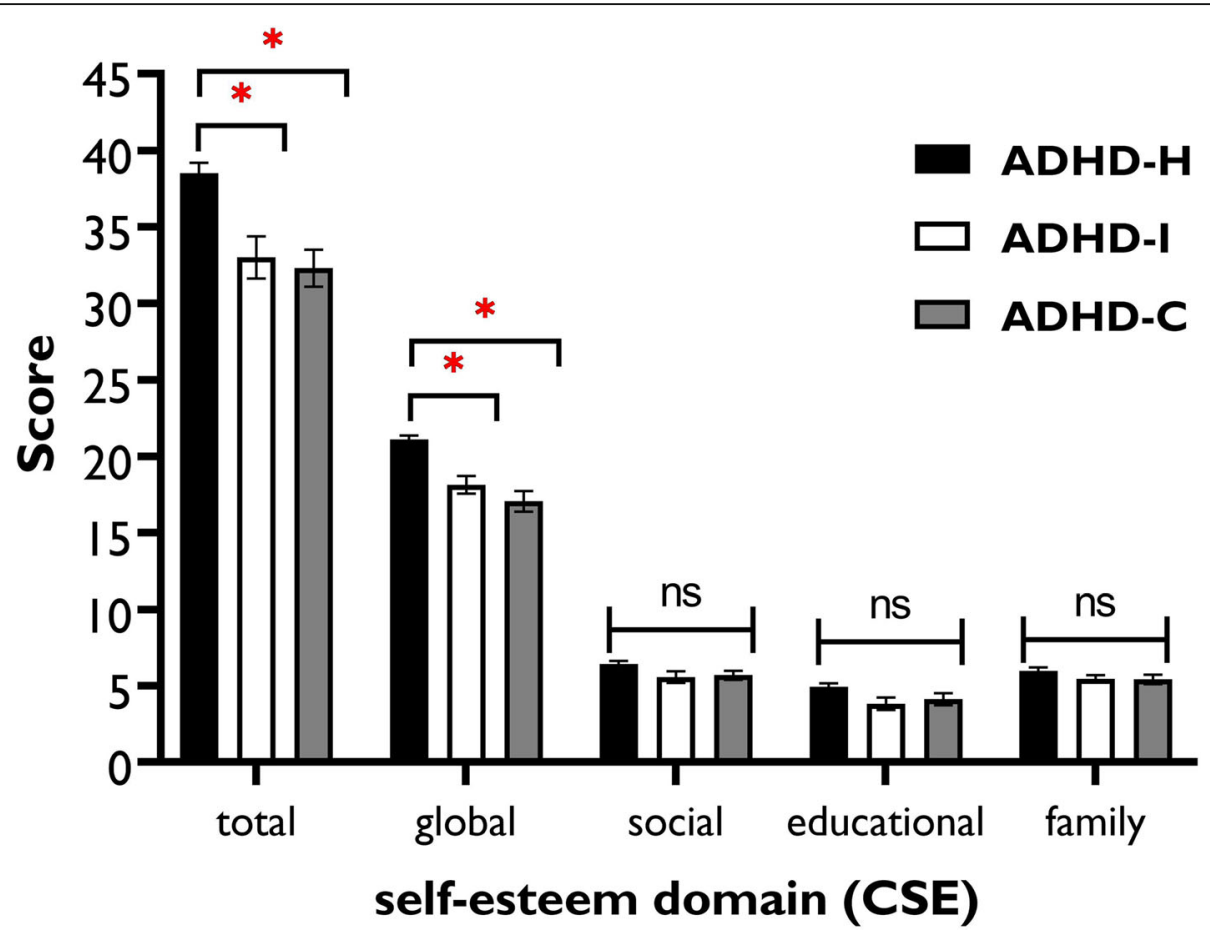

Fig. 2 Mean of the self-esteem domains scores in ADHD subtypes ( $n=139)$ Note: ADHD-H: predominantly hyperactive; ADHD-l: predominantly inattentive; ADHD-C: combined; CSE = Coopersmith self-esteem Inventory; ${ }^{*}=$ indicates significant difference. Post hoc comparisons were conducted using the Bonferroni-corrected post hoc t-tests. All error bars represent standard error of mean (SEM)

An important aspect of our findings was that WM is the poorest cognitive domain in all ADHD subtypes especially in the ADHD-I. Previous studies using the Wechsler Intelligence Scale in both children and adults with ADHD, regardless of subtype, showed that working memory and processing speed are usually among the most impaired domains in ADHD patients compared to healthy controls $[15,21,29,47]$. A recent study that comprehensively examined executive functioning heterogeneity in pediatric
ADHD using neuropsychological battery also found a positive association between impaired working memory and exhibiting higher ADHD symptoms [48]. Our results are generally in line with these studies by showing WM as the most impaired domain in all subtypes. The quantitative pattern observed in cognitive profiles of ADHD subtypes might also suggest that WM is the underlying basic executive function [49] that affects performance on other cognitive domains [50]. More importantly, this is in line

Table 4 Correlational analyses between WISC-IV indices and CSE self-esteem domains

\begin{tabular}{|c|c|c|c|c|c|c|c|c|}
\hline & Global SE & Total SE & Family SE & Social SE & Educational SE & inattention & hyperactivity & ADHD index \\
\hline FSIQ & $0.520^{* *}$ & $0.576^{* *}$ & 0.069 & $0.546^{* *}$ & $0.600 * *$ & $-0.334^{* *}$ & $0.182^{*}$ & -0.156 \\
\hline $\mathrm{VCl}$ & $0.505^{* *}$ & $0.541^{* *}$ & 0.008 & $0.519 * *$ & $0.580^{* *}$ & $-0.256^{* *}$ & $0.203^{*}$ & -0.083 \\
\hline PRI & $0.427^{* *}$ & $0.463^{* *}$ & 0.051 & $0.453^{* *}$ & $0.465^{* *}$ & $-0.379 * *$ & 0.162 & $-0.216^{* *}$ \\
\hline WMI & $0.468^{* *}$ & $0.503^{* *}$ & 0.104 & $0.455^{* *}$ & $0.479 * *$ & -0.166 & 0.076 & -0.078 \\
\hline PSI & $0.391 * *$ & $0.482^{* *}$ & 0.107 & $0.442^{* *}$ & $0.540^{* *}$ & $-0.318^{* *}$ & $0.189^{*}$ & -0.129 \\
\hline Global SE & - & - & - & - & - & $-0.473^{* *}$ & -0.025 & $-0.415^{* *}$ \\
\hline Total SE & - & - & - & - & - & $-0.387^{* *}$ & -0.003 & $-0.303^{* *}$ \\
\hline Family SE & - & - & - & - & - & -0.066 & -0.161 & -0.101 \\
\hline Social SE & - & - & - & - & - & $-0.244^{* *}$ & 0.018 & $-0.177^{* *}$ \\
\hline Educational SE & - & - & - & - & - & $-0.289^{* *}$ & 0.137 & -0.132 \\
\hline
\end{tabular}

Note: WISC Wechsler Intelligence Scale for Children, $A D H D-H$ Predominantly hyperactive, $A D H D-I$ Predominantly inattentive, $A D H D-C$ Combined, VCI Verbal Comprehension Index, PRI Perceptual Reasoning Index, WMI Working Memory Index, PSI Processing Speed Index, FSIQ Full-Scale Intelligence Quotient, SE Selfesteem; All analyses are with Pearson correlation; ${ }^{*}=$ correlation is significant at 0.05 (two-tailed); ${ }^{* *}=$ correlation is significant at 0.01 (two-tailed); Significant results are bolded 
with a recently introduced model of ADHD psychopathology, which proposes WM deficits as a major risk factor in ADHD [51] and implies that WM is probably one of the core cognitive deficits in the pathophysiology of all ADHD subtypes, and could be a reasonable target for ADHD treatment. Novel treatment approaches, such as non-invasive brain stimulation that have been promisingly used in ADHD [5, 6] also target WM as one of the core deficits in ADHD.

In addition to the cognitive correlates, we found a subtype-specific pattern in self-esteem ratings with ADHD-H reporting a higher level of global and total self-esteem compared to other subtypes. Previous studies documented social impairment in ADHD and emphasized on the need for further investigation of subtypespecific social deficits in ADHD [52]. In line with this, our results showed that self-esteem ratings of children with ADHD follow the same quantitative pattern of response in cognitive correlates. In other words, those subtypes with more severe cognitive deficits had the lowest level of self-esteem as well which was supported by the negative correlation between the self-esteem domains and cognitive correlates. The association of subtypespecific cognitive correlates and self-esteem rating is novel and not well-studies by previous works but is in line with studies showing an association between selfesteem and cognitive performance [53, 54].

One important point to be noted here is the distribution of ADHD subtypes in our sample. Participants with the ADHD-H subtype constitute the majority of our sample (51.1\%) while in other studies, the ratio of ADHD-I and ADHD-C has been relatively reported higher $[55,56]$. One potential reason could be that the majority of the sample were boys with ADHD who relatively have a higher ADHD-H subtype ratio than females [57-59] although results have been mixed and some studies show no gender difference between ADHD subtypes. Furthermore, the distribution of ADHD subtype in the Iranian sample does not follow those of western countries [60] and this could be another reason for such a subtype-specific ratio in our sample. Finally, different ratings of symptoms and diagnosis strategy, which can be affected by cultural factors too, could also contribute to higher ADHD-H ratio in our sample.

Taken together, the results of the present study show that there is subtype-specific cognitive profile, measured by WISC-IV, in ADHD confirming a cognitive heterogeneity in ADHD in line with recent evidence [48]. ADHD subtype, if is reliably identified and existed, is an important contributing factor not only to cognitive strength/weakness but also self-esteem ratings. These results have implications for diagnosis precision and personalized treatment in ADHD patients. For instance, cognitive interventions are among the major treatments in ADHD which might be more compatible with and effective in ADHD-I or ADHD-C subtypes due to more severe cognitive weaknesses. Similarly, social interventions and self-esteem can be more effectively addressed in the subtypes with lower self-esteem ratings. The need for the individualized and personalized treatment approach in ADHD is supported more than before from the neurobiological differences of ADHD subtypes [11] and is required due to the heterogeneity of ADHD symptoms.

It is necessary to note that although the focus of this study is on subtype-specific differences in cognitive and self-esteem profiles of children with ADHD, such subtype specification is not confirmed in all studies. Some studies have shown an instability or shift in subtypes over years in children with ADHD [61, 62]. Findings of these studies indicate that ADHD subtypes distinction may not provide a reliable approach for long-term diagnosis and treatment in children with ADHD, especially when the subtype diagnosis is not validated via different measures and assessments. Nevertheless, finding from neuroimaging studies that partially supports a subtypespecific involvement of brain region in ADHD [13, 14] is needed in the future studies along with other neuropsychological measures to validate subtype-specific diagnose in children with ADHD.

The following limitations should be considered. First, we did not have a control group consisting of typically developing children because the purpose of this study was to determine subtype-specific cognitive differences in ADHD. Nevertheless, comparison with typically developing children can also reveal insightful differences of children with ADHD compared to their healthy peers. Second, because we did not intend to focus on gender differences, the number of girls in the study was small and need to be explored in larger samples. Third, the WISC-IV indices might not examine specific aspects of cognition in ADHD and cognitive profile of ADHD subtypes needs to be explored with more specific cognitive measures of executive functions, such as cold vs hot executive functions [63]. Finally, the concept of subtype distinction among children with ADHD is a controversial topic and may not be consistent across the life span which needs to be considered in interpreting the results of this study. These limitations notwithstanding, our ADHD sample were recruited from clinical settings, rather than community, and could have clinical implications.

\section{Conclusions}

We found a subtype-specific quantitative difference in cognitive correlates and self-esteem ratings of children with ADHD which can be considered for precise diagnosis and individualized interventions. Further assessments 
and neuroimaging findings in support of a subtypespecific distinction are needed. Our findings also support the notion that ADHD is characterized by neurocognitive heterogeneity. Cognitive interventions might be more compatible with and effective in inattentive and combined subtypes of ADHD but working memory improving-based interventions can benefit all subtypes. Association of cognitive performance and self-esteem ratings indicates the importance of educational support system in school for children with ADHD and/or providing adjunct supportive interventions in addition to cognitive ones.

\section{Abbreviations}

ADHD: Attention-deficit hyperactivity disorder; ADHD-C: Combined; ADHD$\mathrm{H}$ : Predominantly hyperactive; ADHD-l: Predominantly inattentive; CPRSRS: Conners Parent Rating Scale-Revised Short; DSM-5: Diagnostic and Statistical Manual of Mental Disorders, Fifth Edition; FSIQ: Full-Scale Intelligence Quotient; VCl: Verbal Comprehension Index; PRI: Perceptual Reasoning Index; WMI: Working Memory Index; PSI: Processing Speed Index CSE: Coopersmith self-esteem Inventory

\section{Acknowledgments}

The authors would like to appreciate the staff of the Fatemi Hospital, Child Psychiatry Division.

\section{Authors' contributions}

PM MN \& MAS conceived the study. HS \& MN collected the data. MN and MAS analyzed and interpreted the data. MAS wrote the first draft and designed Figures. MAN, CV, \& MAS revised and reviewed. All authors read and approved the final manuscript.

\section{Funding}

None.

\section{Availability of data and materials}

The datasets used and/or analyzed during the current study are available from the corresponding author on reasonable request.

\section{Ethics approval and consent to participate}

All participants' parents were instructed about experimental procedures and gave their written consent to participate in the study. The protocol was conducted in accordance with the latest version of the Declaration of Helsinki and was approved by the Institutional Review Board and ethical committee at the Ardabil University of Medical Sciences.

\section{Competing interests}

Authors declare no competing interests.

\section{Author details \\ 'Department of Psychiatry, Fatemi Hospital, School of Medicine, Ardabil University of Medical Sciences, Ardabil, Iran. ${ }^{2}$ Department of Scienze Cognitive della Formazione e degli Studi Culturali, University of Messina, Messina, Italy. ${ }^{3}$ Department of Psychology and Neurosciences, Leibniz Research Centre for Working Environment and Human Factors, Dortmund, Germany. ${ }^{4}$ International Graduate School of Neuroscience, Ruhr-University Bochum, Bochum, Germany. ${ }^{5}$ Institute for Cognitive and Brain Sciences, Shahid Beheshti University, Tehran, Iran.}

\section{Received: 24 April 2020 Accepted: 21 September 2020}

\section{Published online: 12 October 2020}

\section{References}

1. Fair DA, Bathula D, Nikolas MA, Nigg JT. Distinct neuropsychological subgroups in typically developing youth inform heterogeneity in children with ADHD. Proc Natl Acad Sci. 2012;109(17):6769-74.

2. Nigg JT. Neuropsychologic theory and findings in attention-deficit/ hyperactivity disorder: the state of the field and salient challenges for the coming decade. Biol Psychiatry. 2005;57(11):1424-35. https://doi.org/10. 1016/j.biopsych.2004.11.011.

3. Willcutt EG, Doyle AE, Nigg JT, Faraone SV, Pennington BF. Validity of the executive function theory of attention-deficit/hyperactivity disorder: a metaanalytic review. Biol Psychiatry. 2005;57(11):1336-46. https://doi.org/10.1016/ j.biopsych.2005.02.006.

4. Colzato LS, Arntz FE. Ritalin. In: Colzato LS, editor. Theory-driven approaches to cognitive enhancement. Cham: Springer International Publishing; 2017. p. $71-80$

5. Salehinejad MA, Wischnewski M, Nejati V, Vicario CM, Nitsche MA. Transcranial direct current stimulation in attention-deficit hyperactivity disorder: a meta-analysis of neuropsychological deficits. PLOS One. 2019; 14(4):e0215095. https://doi.org/10.1371/journal.pone.0215095.

6. Salehinejad MA, Nejati V, Mosayebi-Samani M, Mohammadi A, Wischnewski M, Kuo M-F, et al. Transcranial direct current stimulation in ADHD: a systematic review of efficacy, safety, and protocol-induced electrical field modeling results. Neurosci Bull. 2020. https://doi.org/10.1007/s12264-02000501-x.

7. Roberts BA, Martel MM, Nigg JT. Are there executive dysfunction subtypes within ADHD? J Atten Disord. 2017;21(4):284-93. https://doi.org/10.1177/ 1087054713510349 PubMed PMID: 24214969.

8. Wåhlstedt C, Thorell LB, Bohlin G. Heterogeneity in ADHD: neuropsychological pathways, comorbidity and symptom domains. J Abnorm Child Psychol. 2009;37(4):551-64. https://doi.org/10.1007/s10802008-9286-9.

9. Feczko E, Miranda-Dominguez O, Marr M, Graham AM, Nigg JT, Fair DA. The heterogeneity problem: approaches to identify psychiatric subtypes. Trends Cogn Sci. 2019;23(7):584-601. https://doi.org/10.1016/j.tics.2019.03.009.

10. American Psychiatric Association. Diagnostic and statistical manual of mental disorders (DSM-5 ${ }^{\oplus}$ ): American psychiatric pub; 2013.

11. Rubia K. Cognitive neuroscience of attention deficit hyperactivity disorder (ADHD) and its clinical translation. Front Hum Neurosci. 2018;12(100):1. https://doi.org/10.3389/fnhum.2018.00100.

12. Bluschke A, Schreiter ML, Friedrich J, Adelhöfer N, Roessner V, Beste C. Neurofeedback trains a superordinate system relevant for seemingly opposing behavioral control deficits depending on ADHD subtype. Dev Sci. 2020;1:e12956. https://doi.org/10.1111/desc.12956.

13. McCarthy H, Skokauskas N, Frodl T. Identifying a consistent pattern of neural function in attention deficit hyperactivity disorder: a meta-analysis. Psychol Med. 2013:44(4):869-80Epub 05/13. https://doi.org/10.1017/ S0033291713001037.

14. Solanto MV, Schulz KP, Fan J, Tang CY, Newcorn JH. Event-related fMRI of inhibitory control in the predominantly inattentive and combined subtypes of ADHD. J Neuroimaging. 2009;19(3):205-12. https://doi.org/10.1111/j.15526569.2008.00289x

15. Theiling J, Petermann F. Neuropsychological profiles on the WAIS-IV of adults with ADHD. J Atten Disord. 2016;20(11):913-24. https://doi.org/10. 1177/1087054713518241 PubMed PMID: 24448224

16. Ramos AA, Hamdan AC, Machado L. A meta-analysis on verbal working memory in children and adolescents with ADHD. Clin Neuropsychol. 2019;1: 1-26. https://doi.org/10.1080/13854046.2019.1604998.

17. Thaler NS, Barchard KA, Parke E, Jones WP, Etcoff LM, Allen DN. Factor structure of the Wechsler intelligence scale for children: in children with ADHD. J Atten Disord. 2015;19(12):1013-21.

18. Kaufman AS. Intelligent testing with the WISC-III: John Wiley \& Sons; 1994.

19. Prifitera A, Dersh J. Base rates of WISC-III diagnostic subtest patterns among normal, learning-disabled, and ADHD samples; 1993.

20. Weiss LG, Saklofske DH, Prifitera A, Holdnack JA. WISC-IV advanced clinical interpretation: Elsevier; 2006

21. Moura O, Costa P, Simões MR. WISC-III cognitive profiles in children with ADHD: specific cognitive impairments and diagnostic utility. J Gen Psychol. 2019;146(3):258-82. https://doi.org/10.1080/00221309.2018.1561410.

22. Schwean VL, McCrimmon A. Attention-deficit/hyperactivity disorder: using the WISC-IV to inform intervention planning. WISC-IV Clin Assess intervent 2008;2:193-215

23. Devena SE, Watkins MW. Diagnostic utility of WISC-IV general abilities index and cognitive proficiency index difference scores among children with ADHD. J Appl Sch Psychol. 2012;28(2):133-54. https://doi.org/10.1080/ 15377903.2012.669743.

24. Nydén A, Billstedt E, Hjelmquist E, Gillberg C. Neurocognitive stability in Asperger syndrome, ADHD, and reading and writing disorder: a pilot study. 
Dev Med Child Neurol. 2001;43(3):165-71Epub 04/09. https://doi.org/10. 1017/S0012162201000329.

25. Nigg JT, Blaskey LG, Huang-Pollock CL, Rappley MD. Neuropsychological executive functions and DSM-IV ADHD subtypes. J Am Acad Child Adolesc Psychiatry. 2002;41(1):59-66. https://doi.org/10.1097/00004583-20020100000012.

26. Bussing R, Zima BT, Perwien AR. Self-esteem in special education children with ADHD: relationship to disorder characteristics and medication use. J Am Acad Child Adolesc Psychiatry. 2000;39(10):1260-9. https://doi.org/10. 1097/00004583-200010000-00013.

27. Harpin V, Mazzone L, Raynaud JP, Kahle J, Hodgkins P. Long-term outcomes of ADHD:a systematic review of self-esteem and social function. J Atten Disord. 2016;20(4):295-305. https://doi.org/10.1177/1087054713486516 PubMed PMID: 23698916.

28. Mazzone L, Postorino V, Reale L, Guarnera M, Mannino V, Armando M, et al. Self-esteem evaluation in children and adolescents suffering from ADHD. Clin Pract Epidemiol Ment Health. 2013;9:96-102. https://doi.org/10.2174/ 1745017901309010096 PubMed PMID: 23878614.

29. Alloway TP, Cockcroft K. Working memory in ADHD: a comparison of British and south African children. J Atten Disord. 2014;18(4):286-93.

30. Moura O, Pereira M, Alfaiate C, Fernandes E, Fernandes B, Nogueira S, et al. Neurocognitive functioning in children with developmental dyslexia and attention-deficit/hyperactivity disorder: multiple deficits and diagnostic accuracy. J Clin Exp Neuropsychol. 2017;39(3):296-312.

31. Shahrivar Z, Kousha M, Moallemi S, Tehrani-Doost M, Alaghband-Rad J. The reliability and validity of kiddie-schedule for affective disorders and schizophrenia-present and life-time version-Persian version. Child Adolesc Mental Health. 2010;15(2):97-102.

32. Conners C. Technical manual for the Conners' rating scales-revised. North Tonawanda: Multi-Health Systems; 1997.

33. Conners CK, Sitarenios G, Parker JD, Epstein JN. The revised Conners' parent rating scale (CPRS-R): factor structure, reliability, and criterion validity. J Abnorm Child Psychol. 1998;26(4):257-68.

34. Zarrabi M, Shahrivar Z, Tehrani Doost M, Khademi M, Zargari NG. Concurrent validity of the behavior rating inventory of executive function in children with attention deficit hyperactivity disorder. Iran J Psychiatry Behav Sci. 2015;9(1):e213Epub 02/20. https://doi.org/10.17795/ijpbs213.

35. Kaufman AS, Flanagan DP, Alfonso VC, Mascolo JT. Test review: Wechsler intelligence scale for children, (WISC-IV). J Psychoeduc Assess. 2006;24(3): 278-95.

36. Wechsler D. WISC-IV: administration and scoring manual: psychological corporation; 2003.

37. Walg M, Hapfelmeier G, El-Wahsch D, Prior H. The faster internal clock in ADHD is related to lower processing speed: WISC-IV profile analyses and time estimation tasks facilitate the distinction between real ADHD and pseudo-ADHD. Eur Child Adolesc Psychiatry. 2017;26(10):1177-86. https:// doi.org/10.1007/s00787-017-0971-5.

38. Parke EM, Thaler NS, Etcoff LM, Allen DN. Intellectual profiles in children with ADHD and comorbid learning and motor disorders. J Atten Disord. 2015;0(0):1087054715576343. https://doi.org/10.1177/1087054715576343.

39. Coopersmith S. A method for determining types of self-esteem. J Abnorm Soc Psychol. 1959;59(1):87-94. https://doi.org/10.1037/h0048001.

40. Măroiu C, Maricutoiu LP. Actual self. In: Zeigler-Hill V, Shackelford TK, editors, Encyclopedia of personality and individual differences. Cham: Springer International Publishing; 2017. p. 1-4.

41. Demo DH. The measurement of self-esteem: refining our methods. J Pers Soc Psychol. 1985;48(6):1490-502. https://doi.org/10.1037/0022-3514.48.6.1490.

42. Spatz KC, Johnston JO. Internal consistency of the Coopersmith self-esteem inventory. Educ Psychol Meas. 1973;33(4):875-6. https://doi.org/10.1177/ 001316447303300413

43. Adair FL. Coopersmith self-esteem inventories. Test Critiques. 1984;1:226-32.

44. LeRoy A, Jacova C, Young C. Neuropsychological performance patterns of adult ADHD subtypes. J Atten Disord. 2019;23(10):1136-47. https://doi.org/ 10.1177/1087054718773927 PubMed PMID: 29771179.

45. Dobson-Patterson R, O'Gorman JG, Chan RCK, Shum DHK. ADHD subtypes and neuropsychological performance in an adult sample. Res Dev Disabil. 2016;55:55-63. https://doi.org/10.1016/j.ridd.2016.03.013.

46. August GJ, Garfinkel BD. Behavioral and cognitive subtypes of ADHD. J Am Acad Child Adolesc Psychiatry. 1989;28(5):739-48. https://doi.org/10.1097/ 00004583-198909000-00016.
47. Mayes SD, Calhoun SL. WISC-IV and WISC-III profiles in children with ADHD. J Atten Disord. 2006;9(3):486-93. https://doi.org/10.1177/1087054705283616 PubMed PMID: 16481665.

48. Kofler MJ, Irwin LN, Soto EF, Groves NB, Harmon SL, Sarver DE. Executive functioning heterogeneity in pediatric ADHD. J Abnorm Child Psychol. 2019; 47(2):273-86. https://doi.org/10.1007/s10802-018-0438-2.

49. Nejati V, Salehinejad MA, Sabayee A. Impaired working memory updating affects memory for emotional and non-emotional materials the same way: evidence from post-traumatic stress disorder (PTSD). Cogn Process. 2018; 19(1):53-62. https://doi.org/10.1007/s10339-017-0837-2.

50. Ghanavati E, Salehinejad MA, Nejati V, Nitsche MA. Differential role of prefrontal, temporal and parietal cortices in verbal and figural fluency: implications for the supramodal contribution of executive functions. Sci Rep. 2019;9(1):3700. https://doi.org/10.1038/s41598-019-40273-7.

51. Nigg JT, Gustafsson HC, Karalunas SL, Ryabinin P, McWeeney SK, Faraone SV, et al. Working memory and vigilance as multivariate Endophenotypes related to common genetic risk for attention-deficit/hyperactivity disorder. J Am Acad Child Adolesc Psychiatry. 2018;57(3):175-82. https://doi.org/10. 1016/j.jaac.2017.12.013.

52. Bora E, Pantelis C. Meta-analysis of social cognition in attention-deficit/ hyperactivity disorder (ADHD): comparison with healthy controls and autistic spectrum disorder. Psychol Med. 2015;46(4):699-716Epub 12/28. https://doi.org/10.1017/S0033291715002573.

53. Salehinejad MA, Nejati V, Nitsche MA. Neurocognitive correlates of selfesteem: from self-related attentional bias to involvement of the ventromedial prefrontal cortex. Neurosci Res. 2019:50168-0102(19):30318 https://doi.org/10.1016/j.neures.2019.12.008.

54. Tobia V, Riva P, Caprin C. Who are the children Most vulnerable to social exclusion? The moderating role of self-esteem, popularity, and nonverbal intelligence on cognitive performance following social exclusion. J Abnorm Child Psychol. 2017;45(4):789-801. https://doi.org/10.1007/s10802-016-0191-3.

55. Gaub M, Carlson CL. Behavioral characteristics of DSM-IV ADHD subtypes in a school-based population. J Abnorm Child Psychol. 1997;25(2):103-11. https://doi.org/10.1023/A:1025775311259.

56. Huang $Y$, Zheng $S, X u C$, Lin K, Wu K, Zheng M, et al. Attention-deficit hyperactivity disorder in elementary school students in Shantou, China: prevalence, subtypes, and influencing factors. Neuropsychiatr Dis Treat. 2017;13:785-92. https://doi.org/10.2147/NDT.S126100 PubMed PMID: 28352178.

57. Levy F, Hay DA, Bennett KS, McStephen M. Gender differences in ADHD subtype comorbidity. J Am Acad Child Adolesc Psychiatry. 2005;44(4):36876. https://doi.org/10.1097/01.chi.0000153232.64968.c1.

58. Graetz BW, Sawyer MG, Baghurst P. Gender differences among children with DSM-IV ADHD in Australia. J Am Acad Child Adolesc Psychiatry. 2005;44(2): 159-68. https://doi.org/10.1097/00004583-200502000-00008.

59. Hassanzadeh S, Amraei K, Samadzadeh S. A meta-analysis of attention deficit/hyperactivity disorder prevalence in Iran; 2019.

60. Ghanizadeh A. Psychiatric comorbidity differences in clinic-referred children and adolescents with ADHD according to the subtypes and gender. J Child Neurol. 2009;24(6):679-84. https://doi.org/10.1177/0883073808331086 PubMed PMID: 19491114.

61. Lahey BB, Pelham WE, Loney J, Lee SS, Willcutt E. Instability of the DSM-IV subtypes of ADHD from preschool through elementary school. Arch Gen Psychiatry. 2005;62(8):896-902. https://doi.org/10.1001/archpsyc.62.8.896.

62. Willcutt EG, Nigg JT, Pennington BF, Solanto MV, Rohde LA, Tannock R, et al. Validity of DSM-IV attention deficit/hyperactivity disorder symptom dimensions and subtypes. J Abnorm Psychol. 2012;121(4):991.

63. Nejati V, Salehinejad MA, Nitsche MA, Najian A, Javadi A-H. Transcranial direct current stimulation improves executive dysfunctions in ADHD: implications for inhibitory control, interference control, working memory, and cognitive flexibility. J Atten Disord. 2017;0(0):1087054717730611. https:// doi.org/10.1177/1087054717730611 PubMed PMID: 28938852

\section{Publisher's Note}

Springer Nature remains neutral with regard to jurisdictional claims in published maps and institutional affiliations. 